\title{
Comunicación, Género y Salud. Análisis de un spot publicitario para la detección temprana de cáncer de mama
}

\author{
Leila Martina Passerino \\ Becaria Doctoral Consejo Nacional de Investigaciones Científicas y Técnicas (CONICET) \\ Instituto de Investigaciones Gino Germani - Universidad de Buenos Aires \\ Universidad Nacional de Entre Ríos \\ (Argentina)
}

\begin{abstract}
Palabras clave
Resumen

Spot publicitario

cáncer de mama

prevención

género

androcentrismo

discurso

autocuidado

subjetividad

El trabajo analiza un spot publicitario denominado Por amor a las tetas (Agencia Lowe Porta, 2012) centrado en la detección temprana del diagnóstico cáncer de mama. Desde una perspectiva de género, se trata de mostrar la persistencia de matrices androcéntricas en la organización discursiva del spot y en los modos en que es construida la enfermedad, como también, en la forma en que son interpeladas las mujeres. En términos metodológicos se realiza un análisis crítico del discurso que dialoga con el enfoque teórico propuesto, en relación a los procesos históricos que inciden en la construcción de ciertos modelos ideales de subjetividad femenina y que manifiestan la politicidad y erótica de los cuerpos. La realización de un análisis crítico que vincule las problemáticas de género y subjetividad con las prácticas de salud, resulta fundamental para una aproximación fértil en el campo de la comunicación sobre los sentidos que se construyen y las consecuencias de dichas narrativas. En este plano, se abordan algunas implicaciones para los procesos de aceptación y convivencia del diagnóstico, como así también en vinculación al autocuidado, aspectos fundamentales para el logro de una mayor equidad en la atención y en la promoción de salud.
\end{abstract}

Este trabajo abarca algunas de las discusiones incluidas en el desarrollo una tesis doctoral en curso financiada por el Consejo Nacional de Investigaciones Científicas y Técnicas (CONICET) de Argentina. 


\title{
Communication, Gender and Health. Analysis of an advertisement for the early detection of breast cancer
}

\begin{tabular}{c}
\hline Keywords \\
\hline Advertisement \\
breast cancer \\
prevention \\
gender \\
androcentrism \\
discourse \\
self-care \\
subjectivity
\end{tabular}

\begin{abstract}
The paper analyses an advertisement called For the love of boobs (Lowe Porta Agency, 2012) focused on the early detection of breast cancer. From a gender perspective, the paper shows the persistence of androcentric matrices in the way in which the advertisement's discourse is organized, in which the disease is constructed, and in the manner in which women are engaged. In methodological terms, a critical analysis of the discourse is carried out which discusses the proposed theoretical focus in relation to the historical processes that have influenced the construction of certain subjective ideal female models and which exhibit the politicization and eroticism of their bodies. Within the field of communication, a critical analysis linking issues of gender and subjectivity with health practices is essential in achieving a fruitful approach to the consequences of these narratives and the meanings that result from them. In this regard, the paper discusses some of the implications derived from the processes of acceptance and coexistence with the diagnosis as well as from self-care, all of which are aspects that are essential to achieving greater equality in medical attention and health promotion.
\end{abstract}

\section{Cómo citar el artículo}

Passerino, L. M. (2014). Comunicación, Género y Salud. Análisis de un spot publicitario para la detección temprana de cáncer de mama. Revista de Comunicación y Salud, Vol. 4, pp. 85-97. DOI: http://doi.org/10.35669/revistadecomunicacionysalud.2014.4.85-97 


\section{Introducción}

El trabajo analiza un spot publicitario centrado en la detección temprana del cáncer de mama. Por amor a las tetas (Agencia Lowe Porta, 2012), fue realizado en 2012 en Chile, aunque quitado de circulación rápidamente por las fuertes críticas recibidas, a punto tal que el Ministerio de Salud chileno tuvo que emitir un comunicado sobre la total desvinculación del aviso y su autoría (Sudamericana Hoy, 2012).

Desde este espacio de análisis, se intentará mostrar cómo un spot que puede ser denominado grotesco (en función del mensaje y su viabilización) da cuenta de la persistencia de matrices androcéntricas en la organización de discursos, en los modos en que es construida la enfermedad y son interpeladas las mujeres.

Se proponen para el análisis dos ejes de discusión. En el primer apartado, se realiza una referencia a los procesos históricos que incidieron en la constitución de ciertos modelos ideales de subjetividad femenina. Estos ideales tienen vigencia y participan actualmente en la objetalización de La Mujer (Fernández, 2012), al interior de una lógica patriarcal y androcéntrica, tal como suscribe el spot analizado. En segundo término, se analiza la noción de autocuidado y los sesgos de género que median dicha práctica. Se pone así en tensión, el tipo de comunicación que se promueve desde el spot y algunas limitaciones que inciden en el logro de equidad y empoderamiento de las mujeres desde las prácticas de salud,

\section{La objetalización de La Mujer: dispositivos y consecuencias}

La historia no hay sido nunca lineal y si en los comienzos la dependencia económica, la ignorancia intelectual y pasivización del erotismo de las mujeres fueron las condiciones materiales (....) el reciclaje de la subordinación se realiza no sólo a través de su circulación desventajosa sino especialmente a través del "control de las subjetividades, estableciéndose formas de tutelaje actualizadas, mucho más invisibles pero no menos eficaces" (Fernández, 2012: 20).

El control de subjetividades es un mecanismo complejo. En este caso proponemos analizar un spot publicitario denominado Por amor a las tetas (2012), cuyo propósito inicial se centra en la promoción de la detección precoz de cáncer de mama. Se trata de un spot que en el afán de solucionar una problemática extendida, reproduce y acentúa otra. Desde una mirada desde los estudios de género y subjetividad, se percibe al spot como un soporte narrativo de producción simbólica que actualiza y recicla la subordinación y el tutelaje hacia las mujeres. Se promueve de esta forma, un modelo que recae en la pérdida de autonomía a través de su objetalización y que propone un modo de subjetivación femenina ligado a un ser pasivo, "para los otros", como condición ideal de existencia.

En términos generales, el spot ha sido construido desde una posición patriarcal, es decir, de dominio, en la voz de un sujeto masculino. Si bien podría pensarse como innovadora una campaña que incluye varones en el apoyo y cuidado de las mujeres, esto no es lo que sucede al estar construida desde una voz patriarcal que ubica discursivamente a las mujeres en tanto objeto. 
La campaña propone un impacto prioritariamente visual. Se muestran siempre como centro de escena "tetas", en tomas de corta duración, rápidas y simultáneas. En realidad la operación es más compleja, la mayoría de las tomas focaliza más que "tetas", su insinuación. Lo que se hace es modelar un erotismo al plantear la tensión aparicióndesaparición, una puesta en escena en la cual la atracción se presenta en aquello que se esconde e insinúa.

Si bien se muestran variaciones en las tomas, en las situaciones cotidianas en las cuales las mujeres son enfocadas, en los tipos de escotes y vestimenta utilizada, persisten algunos componentes. Se trata siempre de mujeres "jóvenes", en edad reproductiva, que responden a ciertos cánones de belleza instituidos socialmente, delgadas y con senos que en la mayoría de los casos parecieran estar intervenidos quirúrgicamente o de un tamaño que podría considerarse grande. Esto también sugiere que se exponen a mujeres de clases media/media-alta, capaces de reunir fondos para una cirugía de prótesis mamarias. El spot podría caracterizarse, a grandes rasgos, desde una estética que apunta a destacar el lugar erótico de los senos para las mujeres y su participación en la sexualidad femenina.

Al finalizar la secuencia de imágenes, se leen dos oraciones: "Si tanto nos gustan, deberíamos cuidarlas"; y en un próximo plano se menciona "Incentiva a una mujer a hacerse un examen de mamas". Los sentidos así organizados, abonan a la construcción de cierto modelo de erotismo y sexualidad femenina instituidos como objeto de deseo, como así también a una construcción corporal particular, ambos propuestos desde el recicle y actualización de modelos tradicionales de femineidadi. En la frase "Si tanto nos gustan, deberíamos cuidarlas" se percibe un doble juego, por un lado, mediante una operatoria de condensación, reconoce a las mujeres en tanto "tetas", objetos para la seducción masculina. En esta operatoria, además se promueve un discurso en el cual si la mujer debe cuidarse, debe adquirir conductas saludables o realizar prácticas de autocuidado, será sólo en función del deseo masculino. Pero simultáneamente, incorpora al sujeto masculino, al deslizar la idea de que si les gustan las "tetas" eróticamente, deben verlas como motivo de cuidado en salud de las mujeres que las portan.

Resulta útil en esta instancia tomar alguna de las consideraciones que realiza Teresa de Lauretis (1984). Para esta autora, uno de los temas centrales de la teoría feminista es la construcción de la subjetividad femenina, y en relación a esto, los efectos del lenguaje a partir de los cuales se definen las posiciones de los significados de los sujetos y la reelaboración de esa posición en una construcción subjetiva. La representación se construye al tiempo que lo hace la auto-representación. Desde este marco, la autora se detiene en el cine como soporte material y actividad significante, aparato social a partir del cual se construye subjetividad. El cine, como podríamos pensar el spot que analizamos, controla un campo de significaciones sociales al tiempo que promueve representaciones de género. La femineidad, en este caso, es representada en tanto espectáculo - cuerpo para ser mirado, lugar de la sexualidad y objeto del deseo (Lauretis, 1984: 13).

En esta dirección, Por amor a las tetas promueve un tipo de representación basada en la negativa del sujeto-mujer, estableciendo una valoración jerárquica que promueve la opresión, dado que, al posicionarlas como objeto y fundamento de la representación, 
se las niega a su posición de sujetos y creadoras de cultura (Lauretis, 1984). Estas dos características -estar inscriptas en un orden simbólico patriarcal y además, en un vínculo parcial con el discurso- tiene consecuencias al negarle a la mujer un lugar como sujeta de deseo. En una simbólica patriarcal es la Mujer la representada y no las mujeres (Lombardi, A. s/f: 1), de aquí que sólo haya una relación parcial de las mujeres con el orden simbólico: "La mujer no existe, su existencia es paradojal, ya que al mismo tiempo que se encuentra atrapada en el discurso está ausente de él" (Bach, 1994: 3).

En el spot Por amor a las tetas se utilizan diversos mecanismos para posicionar a la Mujer en tanto Objeto, o lugar de deseo de un otro. Uno de ellos, es la utilización de escenas, que como ya mencionáramos, sólo muestran "tetas" (aún en la insinuación, el foco está en este constructo imaginario y simbólico), es decir, en las tomas, éstas ocupan un primer plano, pero mostrando a su vez parte de los cuerpos de estas mujeres. Este proceso lo que se asegura es el borramiento de todos aquellos rasgos que puedan individualizar a las mujeres que se muestran. El rostro invisibilizado no sólo es lo que no permite el contacto visual con la persona de la imagen, sino que éste participa en la borradura de toda diferencia: todo individuo, incluso el más humilde, lleva su rostro como el mayor signo de su diferencia (Le Breton, 2010). La negación del rostro, se convierte en violencia simbólica al negarle identidad, la objetalización se instituye. Le Breton (2010) explica que toda aparición de un rostro implica un signo del reconocimiento, un rostro socializado y repleto de significación. La negación en el spot de los rostros niega ese lugar de reconocimiento y, por tanto, de igualdad.

Mediante estos mecanismos, se promueve una supresión de la diferencias, más bien de las singularidades, promoviendo la representación de La Mujer, en tanto producción ficticia y reducto de los soportes narrativos de la Episteme de lo Mismo (Fernández, 2012). Se construye en esta operación, una "esencia femenina", las idénticas, en términos de Fernández, que instaura una estrategia basada en la "intercambiabilidad", reforzando el concepto de que las mujeres, al igual que los objetos, son fungibles (Heldman, 2012), es decir, se usan, se descartan, son reemplazadas borrando las singularidades.

Otro de los mecanismos utilizados en pos de la objetivización es el monitoreo y control de los erotismos mediante la presentación de un cuerpo construido que las sitúa como objeto de apropiación, de intercambio, de deseo. Aquí resulta útil reflexionar sobre algunos modos actualizados y adaptados a los modos de subjetivación femenina más contemporáneos, referidos en este caso a la economía del deseo y la relación con el mito tradicional ligado a la pasividad erótica de las mujeres.

El deseo erótico femenino ha tenido un estatuto conflictivo en la cultura, en la medida que siempre se las ha considerado más como objetos deseables que como sujetos/ as deseantes (Meler, 2012: 36). Esta feminidad más pasiva que activa, será también la base para la construcción de una virilidad activa, de un sujeto de deseo masculino, protagonista. La pasividad puede más bien pensarse por tanto, como pasivización, "efecto de la violencia simbólico-institucional sobre el erotismo de las mujeres en el patriarcado, mediante la cual la mujer se alinea de la propiedad, exploración de su cuerpo, registro de sus deseos, búsqueda activa de sus placeres" (Fernández, 2012: 188). 
En el spot publicitario, se visibiliza una Mujer que aparentemente deja de lado esa pasivización tradicional, en la medida que las imágenes deslizan significados ligados al deleite sexual de las mujeres, a la búsqueda de placer. No se explicita el ideal del matrimonio como objetivo de vida para las mujeres, ni tampoco se muestran relaciones que podrían asimilarse a la institución de la monogamia; todas parecieran ser momentos cotidianos (hacer deporte, regar las plantas, trabajar, el lugar del esparcimiento, compartir con otras personas, bañarse, salir a bailar, tener relaciones sexuales, desvestirse y cambiarse la ropa) que podría calificarse en términos amplios como modelos de subjetivación innovadoresii. Sin embargo, una mayor atención al anuncio permite dar cuenta de las transformaciones de los mensajes - para lograr la persistencia de los mitos en torno a la femineidad- en torno a la pasividad o en el control de las subjetividades.

El eslogan final del anuncio "Si tanto nos gustan, deberíamos cuidarlas", reduce la subjetividad de las mujeres y su erotismo a un instrumento del deleite sexual de otra persona. Así, la pretendida actividad y autonomía del erotismo femenino se ve rápidamente delimitada en función de un Otro. Al mismo tiempo, esta aparente apertura en los modos de subjetividad femenina, en realidad reafirman el despliegue particular de erotismo masculino en clave fálica (Fernández, 2012: 253), es decir, el Hombre como garante de una virilidad, sujeto de deseo, protagonista.

En síntesis, se realizan al menos dos lecturas. Por un lado, una visión disciplinar que ubica el cuidado de las "tetas" en tanto soporte de placer de Otro. Simultáneamente, un spot que corre a las mujeres en tanto destinatarias para ubicar a los varones como responsables del cuidado, o más bien, mediante su tutela -mujer como objeto de deseo- promover su salud.

El ideal de maternidad, tampoco será dejado de lado en el anuncio. Se recuerda así, el lugar social privilegiado para La Mujer construida desde el patriarcado, y al mismo tiempo, el lugar del cuidado de los hijos mediante ideales de apego y afecto como características estrictamente femeninas. Este ideal de ternura que disciplina el erotismo y que enfatiza la pasividad es destacado en el spot analizado. La secuencia rápida de imágenes sobre el lugar erótico de las "tetas", se ve interrumpido por un parón en la música de fondo, tras lo cual se exhibe en este plano la imagen de unos "pechos" dando de mamar y el llanto de un niño. Mediante este acto semiótico, se disloca la imagen de las "tetas" -o su insinuación- en tanto lugar imaginarizado erótico, por una construcción más acorde a la noción de ternura, con que son construidos ahora los "pechos" de la mujer. Se evidencia así la operación, en la que a través de la jerarquización del lugar maternal se ha privilegiado históricamente el aspecto reproductor de la mujer en detrimento de su erotismo (Fernández, 2012). Al finalizar esta escena, automáticamente se reanuda la música de fondo que propone el anuncio y la lógica secuencial de las imágenes y los planos.

Los elementos descritos, construyen una heteronomía del cuerpo erótico femenino, que mediante la persistencia de estas imaginerías, relatos y narrativas, producen marcas en la producción de subjetividad de las mujeres. En esta operación, se inaugura la violencia simbólica en torno al monitoreo y control de los erotismos, pero también una normatividad en el modo inscripción de los cuerpos. Así, una problemática que podría 
situarse en un primer momento en el campo de la salud y de las prácticas de cuidado, sirve en realidad como punto de condensación para expresar un conflicto más complejo, que inscribe en los cuerpos, en las subjetividades, modalidades opresivas para las mujeres. Esto supone la consideración del cuerpo desde una dimensión social e histórica, pero simultáneamente, desde su transversalización como apertura a su dimensión política (Fernández, 2007).

El cuerpo construido desde el spot presenta una modalidad de erotismo que lo inscribe en un modelo más bien heterónomo. Desde esta perspectiva, puede considerarse al cuerpo como base de la subjetividad, de modos particulares de subjetivación, atravesado por las marcas de género, en tanto constelaciones discursivas, matriz de hábitos y prácticas, una interpretación de nuestra historia, sujetos de y sujetos a la construcción social (de Lauretis, 1992).

\section{Subjetivación de género y salud: Incidencias en el autocuidado, la equidad y la autonomía de las mujeres.}

Pensar algunas consecuencias de estos discursos y el impacto en la salud de las mujeres constituye una tarea necesaria. Una mirada de género en salud como se propone, implica considerar los costos de los modos de subjetivación femenina que se proponen, en este caso, a partir del spot Por amor a las tetas. Estas modalidades, las cuales construyen modelos ideales de género, impactan diferencialmente en las estrategias de autocuidado de las mujeres, así como en las formas de enfermar, de tramitar sus malestares, en la atención, en la calidad y equidad de atención, entre otros aspectos.

Las significaciones de cuerpo y femineidad concebidas desde una matriz histórica, social y cultural se inscriben en construcciones míticas e ideales normativos. Como ha estudiado Irene Meler (2012) en su trayectoria como psicoanalista en el campo de los estudios de género y salud mental, varones y mujeres se deprimen cuando fracasan en el cumplimiento de las metas tradicionales para su género (Meler, 2012: 33). Muchos de los malestares patologizables pueden reconstruirse en función de ideales normativos o de sus condiciones sociales de emergencia. Como ejemplo histórico, la histeria constituye uno de estos casos: punto de inflexión de los malestares de las mujeres respecto a su lugar social en términos de reproducción y su rol de madres, circunscribía las representaciones de la sexualidad a una pasividad erótica que las privaba de reconocer sus deseos y simultáneamente, su negacióniii. Una mirada de género en salud, resulta por tanto propicia para entender estos modelos diferenciales en el enfermar, como experiencia, pero también frente a las vulnerabilidades propias de los géneros, las oportunidades terapéuticas y las prácticas de autocuidado (Arango, 2000).

En el caso del spot Por amor a las tetas, advertimos que la salud, como derecho ligado al bienestar humano, se plantea siempre en segundo plano, aun cuando se trata de un anuncio para la prevención y detección temprano de tumores en mamas. Si las mujeres deben prestar atención al cáncer de mama, o si los hombres deben incentivarlas -no acompañarlas- a los análisis para una detección precoz, se hace en función 
de preservar el lugar de La Mujer como lugar de deseo masculino y de nutrición de los/as bebes. Este discurso también naturaliza lo femenino como aquel objeto pasivo, recordándole que lo primero no es el bienestar o su salud, sino más bien "el sostenimiento y satisfacción del Otro en una pasividad erótica que al tiempo que exacerba la mítica virilidad masculina, funda el mito que la llave del erotismo de la mujer está en "manos" del hombre" (Fernández, 2012: 250). Como se afirmara, si las mujeres deben estar saludables es solo para sostenerse en tanto objetos de deseo. Para esto el anuncio propone otra operatoria, las objetiva de tal manera -corriéndolas del lugar de sujeto y de las relaciones recíprocas que podrían establecerse entre los géneros- que hace cargo a los varones del incentivo para los exámenes mamarios, se instaura así un modo actualizado de tutelaje. La interpelación es para los varones, negando la representación efectiva de las mujeres y en una operatoria compleja, responsabilizando a ellos mismos, como sujetos masculinos, por la salud de los cuerpos que generan su erotismo: "Si tanto nos gustan, deberíamos cuidarlas", "Incentiva a una mujer a hacerse un examen de mamas".

Este mensaje, a su vez, corre el riesgo de presentar un desenlace que se opone al supuesto fin de la campaña -basado en la promoción de la detección precoz-, producto del miedo al diagnóstico por parte de las mujeres y las consecuencias en sus entornos. Si el entramado del spot sostiene que la mujer debe preocuparse por su salud a fin de no perder su posición en tanto objeto de deseo, no resulta irrisorio que muchas mujeres se nieguen a realizarse los estudios temerosas de ser abandonadas por sus cónyuges, como así también a someterse a los tratamientos requeridos (Frenk, 2009)iv.

En esta misma línea, los factores estéticos y los modelos de belleza presentados en el spot tampoco destacan la promoción de criterios de vida saludable como principal objetivo. Si bien, por ejemplo, en varias escenas se muestra a mujeres realizando actividad física, prevalecen otros propósitos: mostrar el movimiento de los pechos en el ejercicio y ligar la actividad física a la modelización de los parámetros de belleza exigidos por los estereotipos femeninos vigentes. Como se hiciera referencia, se muestran muchos pechos intervenidos por cirugías plásticas, "sosteniendo la sumisión a modelarse a sí misma en torno a un ideal de perfección (...) la belleza será entonces un emblema aceptado por los demás para obtener dominio y cumplir al mismo tiempo con lo que se considera femenina" (Meler, 2012: 44). Asimismo, se trata de un spot que sólo muestra mujeres en edad reproductiva, menores de 40 años, siendo las personas mayores a 50 años quienes representan más del $70 \%$ de diagnósticos de cáncer de mama (INC, 2012). Así, al tiempo que afirma el modelo de Mujer ideal vigente, visibiliza que el objetivo de incentivar prácticas saludables en las mujeres es sólo un objetivo secundario al original al excluirse la población más afectada. Todos estos mecanismos y puestas discursivas en las cuales se construye a La Mujer, configurada sólo en tanto objeto, promueve un tipo de discurso que limita la autonomía en salud, y ligado a esto, su autocuidado y la equidad.

Yolanda Arango (2000) explica que uno de los factores que mayor incidencia tiene en la inequidad de género vigente en el campo de la salud es la simbolización patriarcal. Si la salud, en su complejidad conceptual, puede pensarse como el resultado de los cuidados que una puede dispensarse a sí misma y a la capacidad de decisiones y control de 
su propia vida (Arango, 2007), en el análisis del spot puede advertirse una deficiencia estructural al posicionar a la mujer como objeto y no sujeto de acción. Por tanto, prevalece la inequidad de género en las prácticas de autocuidado de la mujer, entendida como un proceso de empoderamiento ligado a valores reivindicativos de la autoestima, la autodeterminación y el desarrollo humano. La categoría de autocuidado desde los debates de género, continúa la autora, convoca a una actuación protagónica de las mujeres para el ejercicio de ciudadanía en asuntos comprometidos con su vida y el desarrollo humano (Arango, 2000). Por tanto, un anuncio que invisibiliza la capacidad de acción de las mujeres, que sólo las reconoce en tanto objeto para la satisfacción, que subordina la salud en pos de mantener los ideales tradicionales de género y que corre de escena la capacidad de autocuidado, niega esos procesos de empoderamiento y ejercicio ciudadano, favoreciendo la inequidad.

El autocuidado, entendido como la capacidad de las mujeres para decidir sobre su cuerpo y su salud física, mental y emocional en función de su desarrollo humano (Arango, 2000), resulta primordial para revertir la inequidad existente -fundamentada en los parámetros de subjetivación femenina tradicional. De aquí que promover el empoderamiento, la autoestima y la autodeterminación, sea para la autora, el andamiaje sobre el que debe basarse el autocuidado, pero también, en tanto acción política de las mujeres sobre sus cuerpos, sexualidades y erotismos.

Un mensaje no emitido desde una lógica patriarcal y androcéntrica, reivindica la capacidad de decisión que debe ser pensada no sólo como asunto médico, una imposición o un código de conductas que invade la existencia las mujeres en su vivir diario. Arango menciona que el autocuidado se asume como un proceso que tiene que lidiar con la complejidad de la historia de vida personal de las mujeres y sus propios conflictos, generados -desde la lógica patriarcal- en los procesos de socialización y convivencia, que se construyen en los espacios de lo doméstico y por fuera de él (Arango, 2000). El autocuidado se inscribe así como propuesta política.

Que las mujeres puedan optar por las acciones sobre su salud, en su corporalidad, en su sexualidad y erotismo, en sus afectos, como una "relación para sí"; que puedan ser acompañadas en el proceso de enfermedad, que tengan acceso a la información y a la educación sobre prácticas saludables, que la búsqueda de bienestar sea parte de su accionar como sujeta y de su subjetivación como tal, que se autorice a tener deseos propios y opciones de elección, es parte de la reivindicación por la equidad en salud y de la autonomía subjetiva de cada una de las mujeres.

\section{Conclusiones}

Como se ha recorrido, subsisten modos de tutelaje hacia las mujeres que pueden ser analizadas desde el campo de la comunicación y la salud. Las formas actuales de objetalización, promueven modelos de subjetivación que ubican a las mujeres, desde una perspectiva androcéntrica, como objetos de deseo. Esto se evidencia en el spot analizado desde las diversas formas en que es afirmado en el plano del discurso. Los modelos de subjetivación femeninos tradicionales que desde los estudios de género 
se rastrean históricamente desde la Modernidad, participan actualmente y se traslada al plano del cuidado y la salud de las mujeres.

En términos discursivos pueden hacerse al menos dos lecturas. Por un lado, un discurso dirigido a mujeres desde una lógica patriarcal que enfatiza su lugar en tanto objeto de deseo. En esta dirección, la salud se convierte en deber que las obliga a preocuparse por no perder su lugar de ser deseada y simultáneamente, o en términos de no generar preocupación en su entorno -siendo ese sujeto femenino el garante de cuidado en el núcleo familiar. Se desliza también un segundo discurso orientado al sujeto masculino, como responsable del cuidado de la salud de los cuerpos que generan su erotismo.

¿Cuáles son las consecuencias de este discurso? En el caso del spot, se advierte en una primera instancia que la prevención o las prácticas de cuidado de la salud, son dejadas en un lugar secundario. El autocuidado, la capacidad de decisión y control de la vida al ser subsidiarios limitan el ejercicio de la ciudadanía en pos de la reproducción de la subordinación, afectando la autonomía de las mujeres. El autocuidado, que el anuncio desconoce, niega la capacidad de las mujeres para decidir sobre ellas mismas, en relación a sus cuerpos y a las prácticas de salud. Estos aspectos, como se ha intentado subrayar, contiene un trasfondo histórico-cultural con consecuencias materiales para las mujeres. Se advierte así, que a pesar del objetivo inicial del spot, se trata de un anuncio que pone en un lugar suplementario el logro de una eficacia sanitaria en relación a la detección precoz del cáncer de mama.

La realización de un análisis crítico desde el campo de la comunicación, que vincule las problemáticas de género y subjetividad con las prácticas de salud, resulta una aproximación fértil para reflexionar en torno a los sentidos que se construyen y las limitaciones o consecuencias que se deslizan las propuestas producidas.

\section{Notas}

7 El modelo tradicional de femineidad, a partir de la Modernidad, instituye un modelo de mujer la cual debe reprimir su deseo sexual y pasivamente adaptarse a los deseos de los varones (Tajer, 2009:51). Las representaciones de su cuerpo se hayan ligados a ideales belleza y juventud, pero para un otro, para ingresar en el contrato conyugal y para logar un reconocimiento sólo basado en ser objeto de deseo, para otro.

7 El modelo innovador forma parte de una subjetivación femenina más recientes, que atenderían más bien a la diversidad y que incluyen una amplia gama de modalidades, de construcciones subjetivas en las cuales la maternidad y la conyugalidad se plantean como opciones y no como mandatos; la inclusión laboral se constituyen como una condición para el auto sustento. Tienen a su vez una mayor facultad para la expresión erótica, diferenciando entre el goce erótico y el establecimiento de una pareja. La actividad física puede asociarse a la salud pero también a una estética en la cual el que valor no sólo es ser objeto de belleza para otro (Tajer, 2009: 57 ).

iii

7 Cabe destacar que el concepto que trabaja aquí Meler es tomado de las propuestas de Emilce Dio Bleichmar en El feminismo espontáneo de la histeria (1985).Para profundizar sobre la noción de histeria, su construcción histórica, la relación con la medicina y la moral de la época, etc., puede consultarse a su 
vez el trabajo de Ana María Fernández, La Mujer de la llusión (2012), Capítulo 3 ¿Historia de la histeria o histeria de la historia?

7 Débora Tajer (2009), también llega a la conclusión de que la mayoría de las mujeres estudiadas comprendidas en grupos sociales fundamentalmente de sector bajo, quienes compartían un modo de subjetivación de género de tipo tradicional y por tanto concebían un ideal de cuidado del cuerpo ligado sólo a la belleza como objeto valioso para el cotejo matrimonial, tuvieron dificultadas ligadas a estos modos de subjetivación para cuidarse de episodios cardíacos. Como menciona la autora, eso les impidió a ambos grupos cuidarse de un modo diferente de esos parámetros estéticos y establecer para sí criterios de vida saludable y de belleza según las necesidades y posibilidades de cada etapa etaria (Tajer 2009: 123).

\section{Referencias}

Agencia Lowe Porta (Productores) (2012) Por amor a las tetas (Spot publicitario). Chile. Disponible en http://www.poramoralastetas.cl/ Recuperado el 13/02/13.

Althusser, L. (1988) [1969]. Ideología y aparatos ideológicos del Estado. Freud y Lacan. Buenos Aires: Nueva Visión.

Arango, Y. (2000) Autocuidado de la salud: reflexiones desde los aportes de género. Ponencia presentada en el Primer Simposio Internacional de Salud y Género. Sociedad Cubana de Medicina Familiar. Santiago de Cuba.

Arango, Y. (diciembre 2007) Autocuidado, género y desarrollo humano: hacia una dimensión ética de la salud de las mujeres. La manzana de la discordia. Año 2, No. 4. Pp. 107-115. Disponible en http://manzanadiscordia.univalle.edu.co/volumenes/articulos/A2N4/art8.pdf Recuperado el 13/02/13.

Bach, A. M. (1994) La conceptualización del sujeto-mujer en Teresa de Lauretis. En Revista Electrónica Hiparquía. Vol. VII. Disponible en: http://www.hiparquia.fahce. unlp.edu.ar/numeros/volvii/sujeto-sin-genero.-la-conceptualizacion-del-sujeto-mujeren-teresa-de-lauretis/?searchterm=Sujeto\%20sin\%20g\%C3\%A9nero. $\% 20$ La\%20 conceptualizaci\%C3\%B3n\%20del\%20sujeto-mujer\%20en\%20Teresa\%20de\%20Lauretis Recuperado el 13/02/13.

Burin, M., Meler, I. (1998) Género y Familia. Buenos Aires: Paidos.

Burin, M.; Dio Bleichmar, E. (1999) Género, Psicoanálisis, Subjetividad. Buenos Aires: Paidós Psicología Profunda [1996].

Castoriadis, C. (2007) [1975]. La Institución Imaginaria de la Sociedad. Buenos Aires: Ediciones Tusquets.

Dio Bleichmar, E. (1985) El Feminismo Espontaneo de la Histeria. Estudio de los Trastornos Narcisistas de la Feminidad. Madrid: Adotraf.

Dio Bleichmar, E. (2005). La subjetividad en riesgo. Buenos Aires: Topía. 
Fernández, A. M. (2007) Las lógicas colectivas. Imaginarios, cuerpos y multiplicidades. Buenos Aires: Editorial Biblos.

Fernández, A. M. (2009) Orden Simbólico. ¿Orden político? Revista Zona Erógena. Buenos Aires. Disponible en:

http://bibliografia-alternativa.blogspot.com.ar/2009/04/orden-simbolico-orden-politico-ana.html Recuperado el 13/02/13.

Fernández, A. M. (2012) [1993] La mujer de la ilusión. Pactos y contratos entre hombres y mujeres. Buenos Aires: Paidós.

Frenk, J. (2009) Sensibilización, detección temprana y combate a los prejuicios: claves en la lucha contra el cáncer de mama. Salud pública Méx [online]. Vol.51, suppl.2, pp. s135-s137. Disponible en http://www.scielo.org.mx/pdf/spm/v51s2/v51s2a01.pdf Recuperado el 13/02/13.

Guattari, F.; Rolnik, S. (2006) Cartografías del deseo. Madrid: Traficantes de sueños.

Hazaki, C. (Comp.) (2012) La crisis del Patriarcado. Buenos Aires: Editorial Topia.

Heldman, C. (2012). Sexual Objectification, Part 1: What is it? Caroline Heldman's Blog. Disponible en: http://carolineheldman.wordpress.com/2012/07/02/sexual-objectification-part-1-what-is-it/ Recuperado el 13/02/13.

Instituto Nacional del Cáncer, (INC) (2012) Mitos y Verdades. Ministerio de Salud. Presidencia de la Nación. Disponible en: http://www.msal.gov.ar/inc/ciudadanos_mitosyverdades_cancer.php Recuperado el 13/02/13.

De Lauretis, T. (1992) Alicia ya no. Feminismo, Semiótica y Cine. Madrid: Cátedra. Traducción de Silvia Iglesias Recuero.

Lauretis, T. (1984) Alicia ya no. Feminismo, semiótica y cine. Valencia: Ediciones Cátedra.

Le Breton, D. (29 de abril de 2010) Rostro. Página 12. Sección Psicología. Argentina. Disponible en:

http://www.pagina12.com.ar/diario/psicologia/9-144793-2010-04-29.html.

Recuperado el 13/02/13.

Lombardi, A. (s.f.) Orden simbólico, Deseo y Representación Mujer. Agenda de las Mujeres. Disponible en: http://agendadelasmujeres.com.ar/notadesplegada. . $h p$ ? id=3099 Recuperado el 13/02/13.

Meler, I. (2012). Las relaciones de género: su impacto en la salud mental de mujeres y varones. En Hazaki, C. (Comp.) La crisis del Patriarcado. Buenos Aires: Editorial Topia. 
Rosenmberg, M. (1999) [1996] Género y sujeto de la diferencia sexual. El fantasma del feminismo. En Burin, M.; Dio Bleichmar, E. Género, Psicoanálisis, Subjetividad. Buenos Aires: Paidós Psicología Profunda.

Sudamericana Hoy (3 de noviembre de 2012.) "Por amor a las tetas", el vídeo de la polémica en Chile. Disponible en: http://www.sudamericahoy.com/pais-chile/por-amora-las-tetas-el-video-de-la-polemica-en-chile/ Recuperado el 13/02/13.

Tajer, D. (2009) Heridos Corazones. Vulnerabilidad coronaria en varones y mujeres. Buenos Aires: Paidós. 